\title{
High-performance of sodium carboxylate-derived materials for electrochemical energy storage
}

\author{
Yong $\mathrm{Xu}^{1}$, Jun Chen ${ }^{1 *}$, Caijian Zhu ${ }^{1}$, Pengwei Zhang ${ }^{1}$, Guoxiang Jiang ${ }^{1}$, Chunxiang Wang ${ }^{1}$, \\ Qian Zhang ${ }^{1}$, Nengwen Ding ${ }^{1}$, Yaxiang Huang ${ }^{2}$ and Shengwen Zhong ${ }^{1 *}$
}

\begin{abstract}
Four types of sustainable sodium carboxylatederived materials are investigated as novel electrodes with high performance for lithium-ion batteries. Benefiting from the porous morphology provided by their intermolecular interactions, increasing capacity, excellent cycle stability and superior rate performance are observed for the sodium carboxylate-derived materials. The sodium oxalate ( $\mathrm{SO}$ ) electrodes displayed an increasing discharging capacity at a current density of $50 \mathrm{~mA} \mathrm{~g}^{-1}$ with maximum values of $242.9 \mathrm{~mA} \mathrm{~h} \mathrm{~g}^{-1}$ for SO-631 and $373.9 \mathrm{~mA} \mathrm{~h} \mathrm{~g}^{-1}$ for SO-541 during the $100^{\text {th }}$ cycle. In addition, the SO-541, SC-541 (sodium citrate), ST541 (sodium tartrate) and SP-541 (sodium pyromellitate) electrode materials displayed high initial capacities of 619.6, $392.3,403.7$ and $278.1 \mathrm{~mA} \mathrm{~h} \mathrm{~g}^{-1}$, respectively, with capacity retentions of $179 \%, 148 \%, 173 \%$ and $108 \%$, respectively, after 200 cycles at $50 \mathrm{~mA} \mathrm{~g}^{-1}$. Even at a high current density of $2,000 \mathrm{~mA} \mathrm{~g}^{-1}$, the capacities remain $157.6,131.3,146.6$ and $137.0 \mathrm{~mA} \mathrm{~h} \mathrm{~g}^{-1}$, respectively. With these superior electrochemical properties, the sodium carboxylate-derived materials could be considered as promising organic electrode materials for large-scale sustainable lithium-ion batteries.
\end{abstract}

Keywords: sodium carboxylate, lithium-ion batteries, organic electrode, electrochemical performance, green and sustainable

\section{INTRODUCTION}

During the past two decades, great successes have been achieved for lithium-ion batteries because of their advantageous comprehensive performance. The rapid development of power battery systems has imposed stricter requirements on the performance of lithium-ion batteries [1-3]. However, current energy storage systems mainly depend on the substantial use of electrode materials that are far from renewable or sustainable, such as inorganic compounds with rare metals (e.g., $\mathrm{Ni}, \mathrm{Co}$ and $\mathrm{Mn}$ ) that originate from limited mineral resources [4-7]. To meet the requirements for a sustainable development and environmental conservation, it remains a significant challenge to pursue renewable and sustainable electrode materials.

Organic electrode materials can provide reversible redox reactions and can be synthesized from biomass materials, are considered as promising candidates for use in large-scale lithium-ion batteries [8-10]. In recent years, organic anode and cathode materials have received significant research attention [11-13]. Some organic compounds [14-17] with special structures, such as conductive polymers, sulfur and nitrogen compounds, as well as carbonyl conjugated compounds, have been designed, and their energy storage performances and electrochemical reaction mechanisms have been investigated, offering new concepts in this area. Among them, organic carbonyl salts [18-20] have the advantages of structural diversity, high capacity, and fast redox reaction kinetics due to their large conjugated systems and multiple carbonyl functional groups, which is of broader concern in their roles as emerging electrochemical energy-storage materials.

However, for the organic electrode materials, low conductivity and high solubility in electrolytes are the most critical issues related to their utilization in lithiumion batteries, which results in poor cycling performance. Among the various methods to address these problems, the lithiation of organic molecules is an effective method for inhibiting the dissolution of organic electrode materials in electrolytes [21-25], along with doping a large number of conductive agents [26,27] or using large ring conjugated systems [28-30] to increase the electrical

${ }^{1}$ School of Materials Science and Engineering, Key Laboratory of power battery and materials, Jiangxi University of Science and Technology, Ganzhou 341000, China

${ }^{2}$ Guangdong Jiana Energy Technology Co Ltd, Guangzhou 511495, China

* Corresponding authors (emails: chenjun@iccas.ac.cn (Chen J); zhongshw@126.com (Zhong S)) 

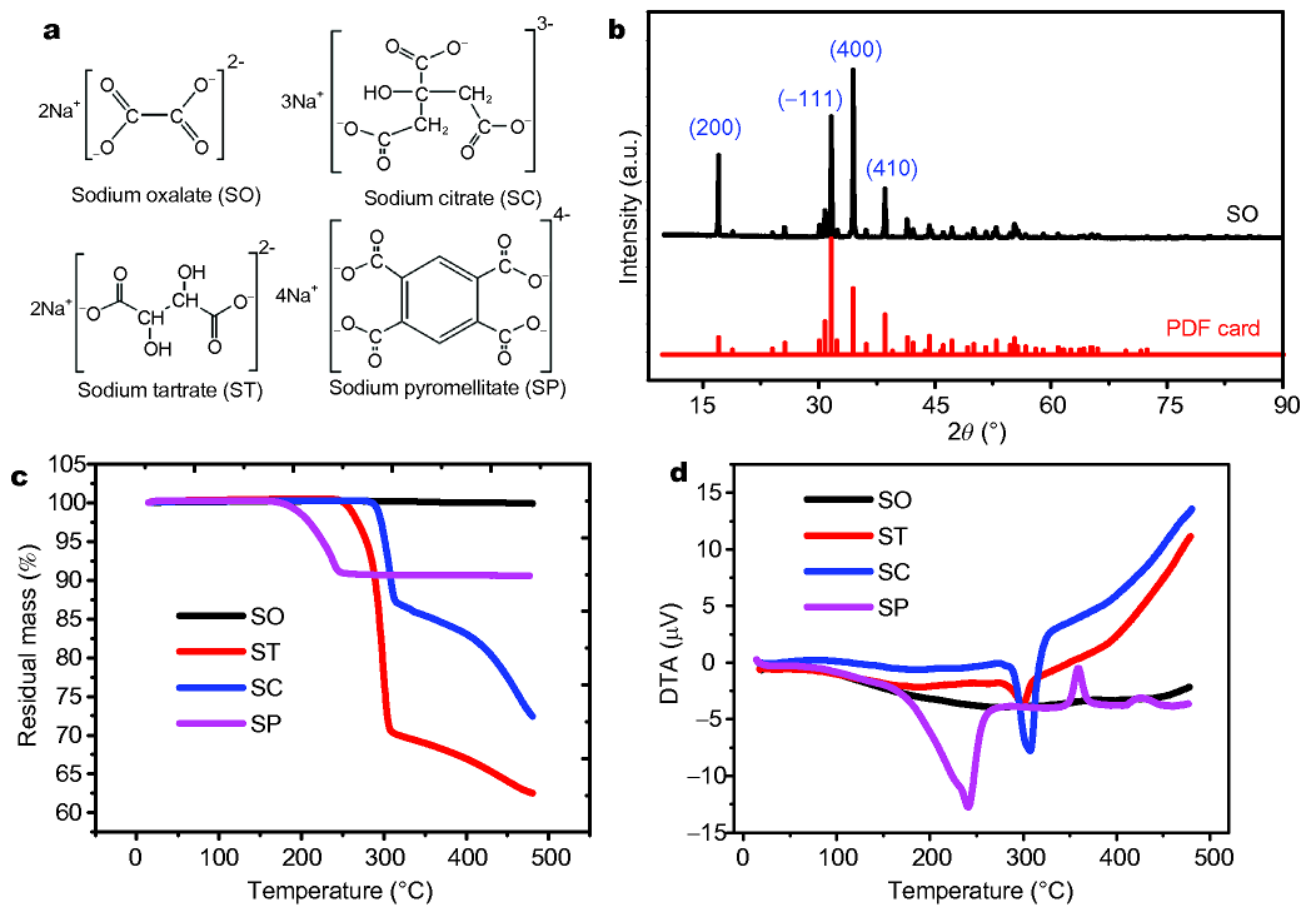

Figure 1 (a) Chemical formula of four types of sustainable sodium carboxylate-derived materials (SO, SC, ST and SP); (b) XRD patterns of sodium oxalate (SO); TGA-DTA thermal analysis tests of SO, SC, ST and SP samples: (c) TGA curves; (d) DTA curves.

conductivity. However, in addition to the two important indicators of conductivity and solubility, the storage, sustainability, and cost of electrode materials for lithiumion batteries are also important parameters influencing their application prospects. Renewable biomass materials and their derivatives have been considered as possible alternatives to the traditional non-sustainable inorganic and organic electrode materials $[9,13]$. Among them, oxalic acid, citric acid, and tartaric acid are the metabolic products of organisms and are widely distributed in plants, animals, and fungi all over the world, and these materials can be considered as sustainable green organic electrode materials with good application prospects. Therefore, in this manuscript, sodium oxalate (SO), sodium citrate (SC), sodium tartrate (ST) and sodium pyromellitate (SP) (Fig. 1a) were exploited as novel electrode materials, and their electrochemical properties were systematically investigated and analyzed, providing new concepts for the exploration of high-performance, sustainable and low-cost organic green electrode materials.

\section{EXPERIMENTAL SECTION}

\section{Materials and methods}

The polycarboxylic acid sodium salts and all other re- agents were of analytical grade and used directly without any further purification. Scanning electron microscopy (SEM) images were captured using a ZEISS Crossbeam 340 scanning electron microscope. Before the electrochemical performance was tested, all cells were pretreated by discharging them against lithium from their opencircuit voltage $\left(V_{\mathrm{OC}}\right)$ to $0.01 \mathrm{~V}$ at a current density of $25 \mathrm{~mA} \mathrm{~g}^{-1}$ and finally charging them against lithium to $3.5 \mathrm{~V}$ at the same rate. The electrochemical performance was tested using a $5 \mathrm{~V} / 10 \mathrm{~A}$ type of electrochemical performance tester produced by Shenzhen Neware Electronics Co., Ltd. The capacity was calculated according to the mass of sodium carboxylate-derived materials. Cyclic voltammograms (CVs) were recorded by a Solatron 1260/ 1287 Electrochemical Interface (Solatron Metrology, UK) at a scan rate of $0.1 \mathrm{mV} \mathrm{s}^{-1}$ between 0.01 and $3.0 \mathrm{~V}$. Impedance analyses were also performed under a frequency range from $10 \mathrm{MHz}$ to $0.001 \mathrm{~Hz}$ with a vibration voltage of $5 \mathrm{mV}$ using a Solatron 1260/1287 Electrochemical Interface kit.

\section{Preparation of the electrode sheet and battery assembly} The raw materials SO, SC, ST and SP were first dried at $120^{\circ} \mathrm{C}$ for $24 \mathrm{~h}$ to remove the crystalliferous water and then milled and sieved. The obtained small powders were 


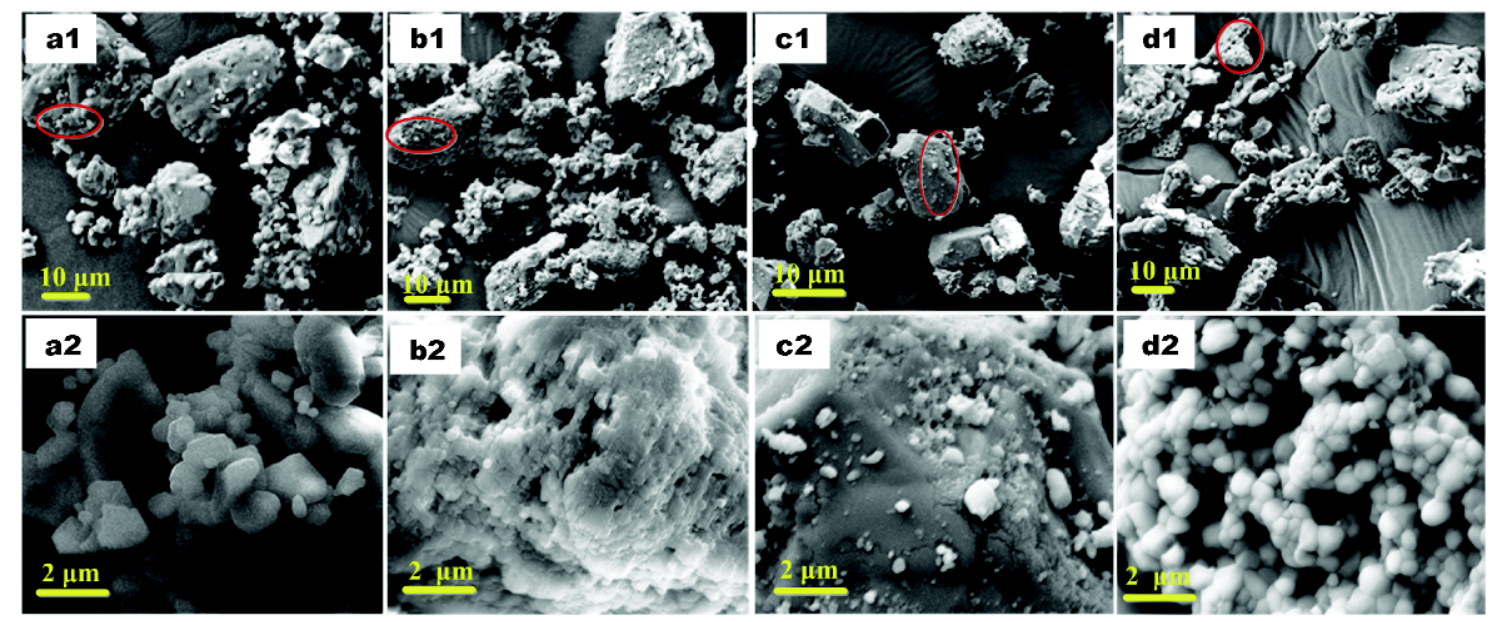

Figure 2 SEM images of the four polycarboxylic acid sodium materials: SO (a1, a2), SC (b1, b2), ST (c1, c2), and SP (d1, d2).

further dried at $120^{\circ} \mathrm{C}$ for another $48 \mathrm{~h}$ under vacuum to obtain the fully dried powder.

The coin cells for the experiment were assembled by a similar method to our published papers [26-28]. A slurry of $70 \mathrm{wt} \%$ (or $60 \mathrm{wt} \%$ ) electrode sample, $30 \mathrm{wt} \%$ (or 40 $\mathrm{wt} \%)$ conductive carbon black SP and $10 \mathrm{wt} \%$ polyvinylidene fluoride (PVDF) was coated onto the copper foil. After drying at $120^{\circ} \mathrm{C}$ for $4 \mathrm{~h}$ and at $60^{\circ} \mathrm{C}$ overnight under vacuum, the electrode was cut into circular pieces with diameter of $1.2 \mathrm{~cm}$ for coin cell testing, and the area mass loading of the electrode was approximately $10 \mathrm{~m} \mathrm{~cm}^{-2}$. The lithium-ion batteries were assembled using lithium metal as the counter electrode, $1 \mathrm{~mol} \mathrm{~L}^{-1}$ $\mathrm{LiPF}_{6}$ in a mixture of ethylene carbonate/diethyl carbonate (EC/DEC, 1:1 by volume) as the electrolyte, and Celgard 3501 (Celgard, LLC Corp., USA) as the separator.

\section{RESULTS AND DISCUSSION}

\section{Characterization and stability analysis}

It is reported that small molecular carbonyl compounds are readily dissolved in electrolyte solvents, resulting in poor cycle stability [31,32]. However, in present work, the sodium carboxylate-derived materials of SO, SC, ST and SP (Fig. 1a) have very low solubility in organic electrolyte solvents, and this would result in the excellent stability of these salts as electrode materials. The lithium salt or sodium salt of carbonyl compounds is an effective way to enhance the cycle stability [21,22].

Fig. $1 \mathrm{~b}$ shows the XRD patterns of SO sample. It can be seen that the strongest peak $\left(2 \theta=31.6^{\circ}\right)$ corresponds to the characteristic diffraction peak of SO $(-111)$ crystal plane with lattice spacing of $2.9 \AA$. The second strong peak $\left(2 \theta=34.4^{\circ}\right)$ corresponds to the characteristic diffraction peak of SO (400) crystal plane with lattice spacing of $2.6 \AA$, and the third strong peak $\left(2 \theta=17.0^{\circ}\right)$ is the characteristic diffraction peak of SO (200) crystal plane with lattice spacing of $5.2 \AA$. These interlamellar spacings are very close to the interlayer spacing of graphite $(3.3 \AA)$, which are very suitable for the intercalation and removal of lithium ions, and would be also another important factor in generating capacity contributions.

In order to analyze the thermal stability of the carboxylic acid sodium salts, the thermogravimetric analysis (TGA) and differential thermal analysis (DTA) were carried out. As shown in Fig. 1c, d, all samples are heated from room temperature to $500^{\circ} \mathrm{C}$, and the TGA curve coincides well with the DTA curve. It was found that the SO sample has the best thermal stability, and there has never been a decomposition peak. The decomposition peak for the ST, SC and SP samples are at 290, 300 and $190^{\circ} \mathrm{C}$, respectively. All the samples display good thermal stability and are suitable for the operating temperature range of electrode materials.

\section{SEM images}

The morphology and microstructure of the four polycarboxylic acid sodium materials were investigated by SEM. Fig. 2 shows that the SO powders clearly possess globular morphologies with multilayered microspheres (approximately $1 \mu \mathrm{m}$ ) stacked together to form a cluster of loose, porous structures with different particle sizes of 5-12 $\mu \mathrm{m}$. In contrast to SO powders, the SC and ST samples present block-like morphologies with multi- 
layered, disordered, and small particles stacked together to form a cluster of loose, porous structures with various particle sizes of 5-30 $\mu \mathrm{m}$. The SP sample shows the similar morphology and stacking form as those of SO, which also accumulates as small globular particles to form a cluster of loose, porous structures with different particle sizes of approximately 5-20 $\mu \mathrm{m}$.

The morphology and microstructure of a compound are closely related to its molecular structure. Fig. 1a shows that the molecular structures of SO and SP are highly symmetrical and that the conjugated structure of their molecules facilitates $\pi$-electron interactions to form an orderly arrangement. A molecular structure with high symmetry results in better regularity and a greater probability of forming highly ordered lattices, which can be confirmed by the XRD patterns of SO sample (Fig. 1b). Therefore, the SO and SP salts have a higher degree of molecular arrangement and crystallinity, explaining why the SO and SP samples show the stacking of regular spherical particles to form a porous structure, as shown in Fig. 2a, d. The SC and ST salts have more alkyl chains in their molecular structure than those in the other salts; less interaction occurs between molecules, and the disorder in their molecular arrangement is greater, explaining why the SC and ST samples exhibit a loose, porous, disordered structure, as shown in Fig. 2b, c.

\section{Cyclic voltammetry curves}

The coin cells were assembled using the as-treated polycarboxylic acid sodium salt as the electrode material. CV measurements of the samples with different amounts of conductive agents were performed in the voltage range of 0.01 to $3.5 \mathrm{~V}$ with a scan rate of $0.1 \mathrm{mV} \mathrm{s}^{-1}$, as shown in Fig. 3. All four polycarboxylic acid sodium electrodes exhibit similar CV curves with similar shapes and areas. There are no obvious redox peaks observed in contrast to traditional metal oxide electrode materials, and all samples show much higher current responses at the lower voltage range of 0.01 to $1.5 \mathrm{~V}$ and much lower current responses at the higher voltage range of 1.5 to $3.5 \mathrm{~V}$, indicating that the polycarboxylic acid salts would be based on a special lithium storage mechanism. For carbonyl compounds, the opening and closing of the double bonds of the carbonyl groups [33] will contribute to the capacity of the battery. In addition, as discussed in XRD patterns of Fig. 1b, the samples of polycarboxylic acid salts have the lattice spacing similar to graphite, which are very suitable for the intercalation and removal of lithium ions, and would be also another important factor in generating capacity contributions.

\section{Electrochemical impedance spectroscopy}

Electrochemical impedance spectroscopy (EIS) was carried out to illustrate the mechanism of the lithium storage process. The Nyquist plots of the SO, SC, ST and SP electrodes after three cycles are compared in Fig. 4a, b. Usually, the obtained Nyquist plots reflect the overall response of the electrochemical process of the carbonyl groups reacting with $\mathrm{Li}^{+}$; these plots primarily consist of a semicircle in the high/medium-frequency range and a straight line in the low-frequency range. The Nyquist plots were fitted using the equivalent circuit, as shown in Fig. $4 \mathrm{c}$, where $R_{1}$ reflects the transfer resistance of lithium ions in the electrolyte and the contact resistance of the battery shell, $R_{2}$ is the interface resistance caused by the solid electrolyte interface (SEI) film double layer. $R_{3}$ is the charge-transfer resistance during the electrochemical reaction process. $W_{1}$ represents the Warburg impedance concerning the diffusion of $\mathrm{Li}^{+}$into the bulk electrode and $C_{1}$ and $C_{2}$ represent the constant phase elements that are used to cancel the measurement error and hysteresis effect $[30,34]$.

On the basis of the fitting parameters listed in Table 1, the $R_{1}$ values of all samples are similar because of using the same electrolyte. The $R_{3}$ values are 102.7, 78.0, 109.9 and $177.0 \Omega$ for SO, SC, ST and SP, respectively, with a 30 $\mathrm{wt} \%$ conductive agent and 33.4, 52.2, 52.7 and $59.8 \Omega$ for SO, SC, ST and SP, respectively, with a $40 \mathrm{wt} \%$ conductive agent. The $R_{3}$ values of the electrodes with the $40 \mathrm{wt} \%$ conductive agent are much lower than those of the electrodes with the $30 \mathrm{wt} \%$ conductive agent. The same trend can also be observed in the values of $W_{1}$, in which the electrodes with the $40 \mathrm{wt} \%$ conductive agent present much lower values of $W_{1}$. These results demonstrate that as the conductive agent amount increases, the interface resistance caused by the charge-transfer resistance $\left(R_{3}\right)$ and the diffusion resistance of $\mathrm{Li}^{+}$in the electrode sheet $\left(W_{1}\right)$ greatly decreased, which will result in a better electrochemical performance.

\section{Charge/discharge performance}

Fig. 5 show the charging/discharging curves of the four polycarboxylate electrodes at a current density of $50 \mathrm{~mA} \mathrm{~g}^{-1}$ in the voltage range from 0.01 to $3.5 \mathrm{~V}$. It can be seen that all the discharging curves of the four electrodes display two platforms at approximately $0.01-1.2 \mathrm{~V}$ and $1.2-3.5 \mathrm{~V}$, suggesting that a two-step process occurred for the insertion and removal of lithium ions, which can also be demonstrated by the two cathodic peaks discussed in the CV curves (Fig. 3). The discharge capacities are 188.1, 165.8, 175.8 and $184.7 \mathrm{~mA} \mathrm{~h} \mathrm{~g}^{-1}$ for 

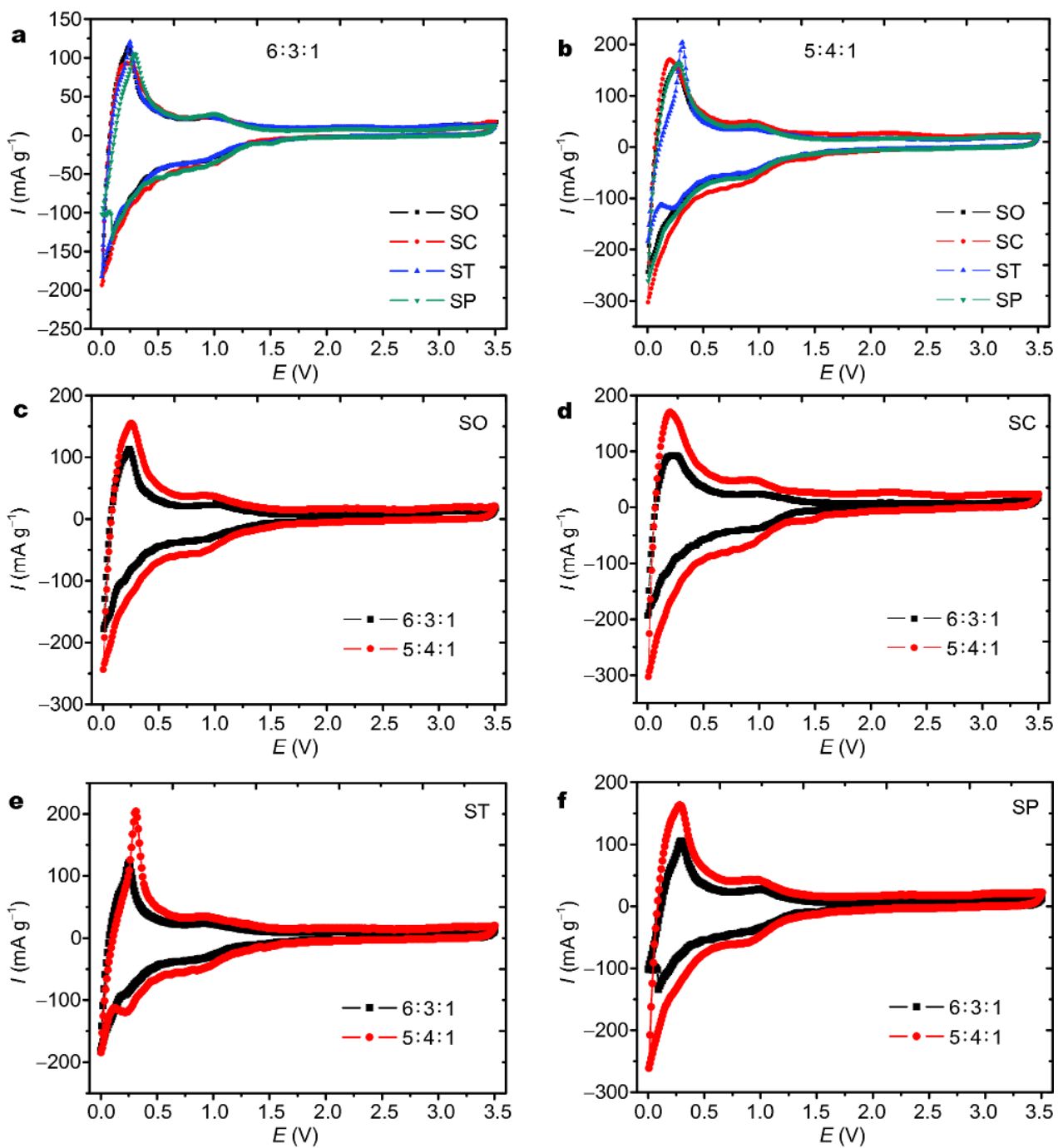

Figure $3 \mathrm{CV}$ curves of four polycarboxylic acid sodium samples (0.01-3.5 V) (a) $30 \mathrm{wt} \%$ conductive agent; (b) $40 \mathrm{wt} \%$ conductive agent; (c-f) contrast diagrams of four samples with two different content of conductive agents.

the SO, SC, ST and SP electrodes, respectively, using the $30 \mathrm{wt} \%$ conductive agent and 315.6, 259.5, 229.9 and $235.7 \mathrm{~mA} \mathrm{~h} \mathrm{~g}^{-1}$ for the SO, SC, ST and SP electrodes, respectively, using the $40 \mathrm{wt} \%$ conductive agent. With an increase in the conductive agent amount from $30 \mathrm{wt} \%$ to $40 \mathrm{wt} \%$, the conductivity of the electrode increases (Fig. 4 and Table 1) and more active sites are excited, resulting in higher charge/discharge capacities.

\section{Cycling performance}

The cycle performance of the four polycarboxylate electrodes using different ratios of conductive agent was investigated by charging/discharging at a current density of $50 \mathrm{~mA} \mathrm{~g}^{-1}$ in a voltage range from 0.01 to $3.5 \mathrm{~V}$, as shown in Fig. 6 and Table 2. For the electrodes using the $30 \mathrm{wt} \%$ conductive agent, similar initial discharge capacities are observed with values of $187.9, \quad 186.8 \quad 182.3$ and $182.4 \mathrm{~mA} \mathrm{~h} \mathrm{~g}^{-1}$ for SO, SC, ST and SP, respectively. In the first 8 cycles, the capacities of all samples decrease gradually and then increase slowly. After 200 cycles, the four samples exhibited increasing capacities of 354.2, 188.8, 295.3 and $246.1 \mathrm{~mA} \mathrm{~h} \mathrm{~g}^{-1}$, respectively, with capacity retentions of $188 \%, 101 \%, 162 \%$ and $135 \%$, respectively. For the batteries using the $40 \mathrm{wt} \%$ conductive agent (Fig. 6b), the initial discharge capacities are 345.6, 264.9, 232.8 and $256.9 \mathrm{~mA} \mathrm{~h} \mathrm{~g}^{-1}$ for SO, SC, ST and SP, respectively. These capacities then decrease slowly, and after 200 cycles, the SO, SC, ST and SP electrodes exhibit excellent capacities 

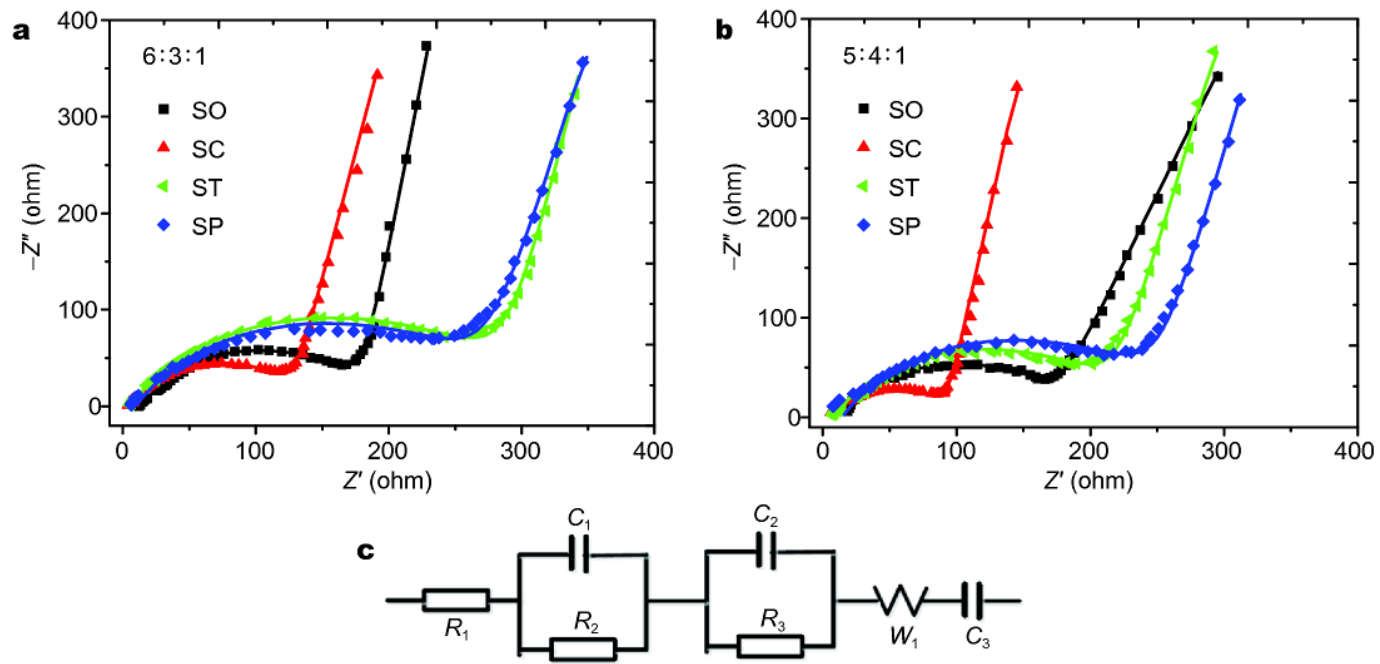

Figure 4 Nyquist plots of the four polycarboxylic acid sodium samples with different contents of conductive agent: (a) 30 wt $\%$ conductive agent and (b) $40 \mathrm{wt} \%$ conductive agent. (c) The modified Voigt-FMG equivalent circuit diagram.
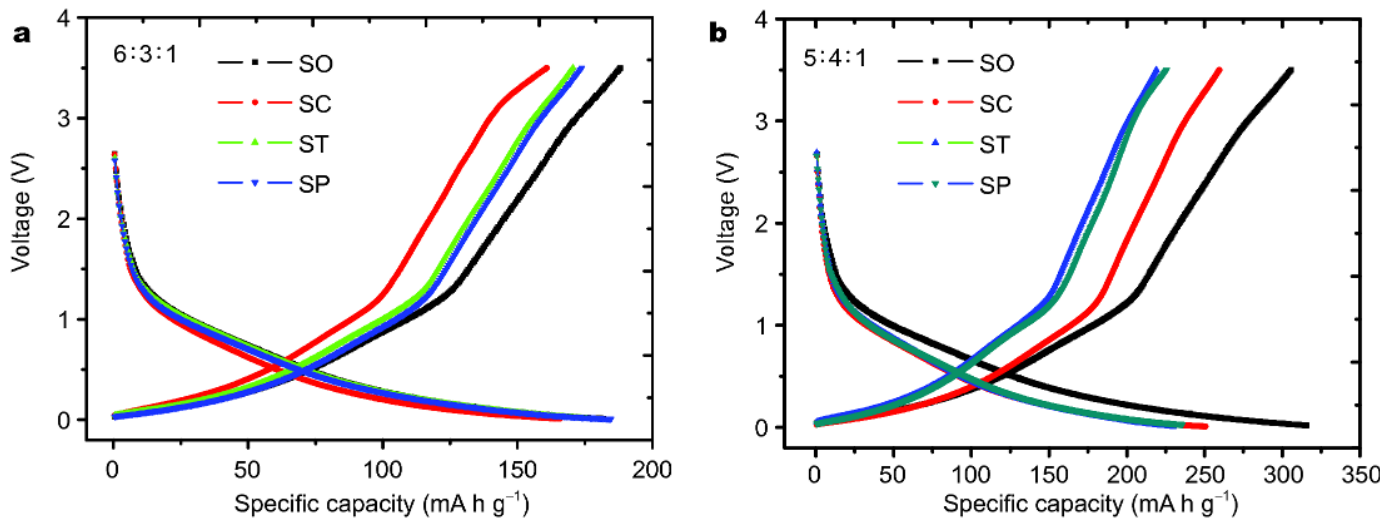

Figure 5 Initial charge/discharge curves of SO, SC, ST and SP with different ratios of conductive agent: (a) 6:3:1 and (b) 5:4:1.

Table 1 List of EIS fitting parameters of the four polycarboxylic acid sodium samples with different contents of conductive agent

\begin{tabular}{ccccc}
\hline Samples & $R_{1}$ (error) $(\Omega)$ & $R_{2}$ (error) $(\Omega)$ & $R_{3}$ (error) $(\Omega)$ & $W_{1}$ (error) $(\Omega)$ \\
\hline SO (5:4:1) & $16(14.8 \%)$ & $47.6(19.5 \%)$ & $33.4(28 \%)$ & $0.00355(3.3 \%)$ \\
SO (6:3:1) & $15.6(6.4 \%)$ & $36.6(7.7 \%)$ & $102.7(2.7 \%)$ & $0.00547(4.1 \%)$ \\
SC (5:4:1) & $9.18(30.4 \%)$ & $11.9(28.4 \%)$ & $52.2(4.8 \%)$ & $0.00399(3.1 \%)$ \\
SC (6:3:1) & $4.49(29.7 \%)$ & $23.2(12.6 \%)$ & $78.0(3.5 \%)$ & $0.00401(3.9 \%)$ \\
ST (5:4:1) & $12.3(10.8 \%)$ & $107.7(3.6 \%)$ & $52.7(7.5 \%)$ & $0.00367(2.9 \%)$ \\
ST (6:3:1) & $11.9(15.7 \%)$ & $118.2(5.9 \%)$ & $109.9(6.4 \%)$ & $0.00390(3.8 \%)$ \\
SP (5:4:1) & $14.6(16.7 \%)$ & $116.7(5.8 \%)$ & $59.8(11.4 \%)$ & $0.00292(3.2 \%)$ \\
SP (6:3:1) & $13.0(44.3 \%)$ & $25.2(31.9 \%)$ & $177.0(4.2 \%)$ & $0.00295(6.1 \%)$ \\
\hline
\end{tabular}

of $619.6,392.3,403.7$ and $278.1 \mathrm{~mA} \mathrm{~h} \mathrm{~g}^{-1}$, respectively, with capacity retentions of $179 \%, 148 \%, 173 \%$ and $108 \%$, respectively.

For all electrodes, the cause of the transient attenuation of the initial capacity is the formation of an SEI film that consumes part of the irreversible capacity. In addition, because the particle size of carboxylic acid sodium salt is very uneven (see Fig. 2), the partial active sites, especially the active sites inside the large particles, are difficult to be fully activated. This phenomenon occurs when the con- 

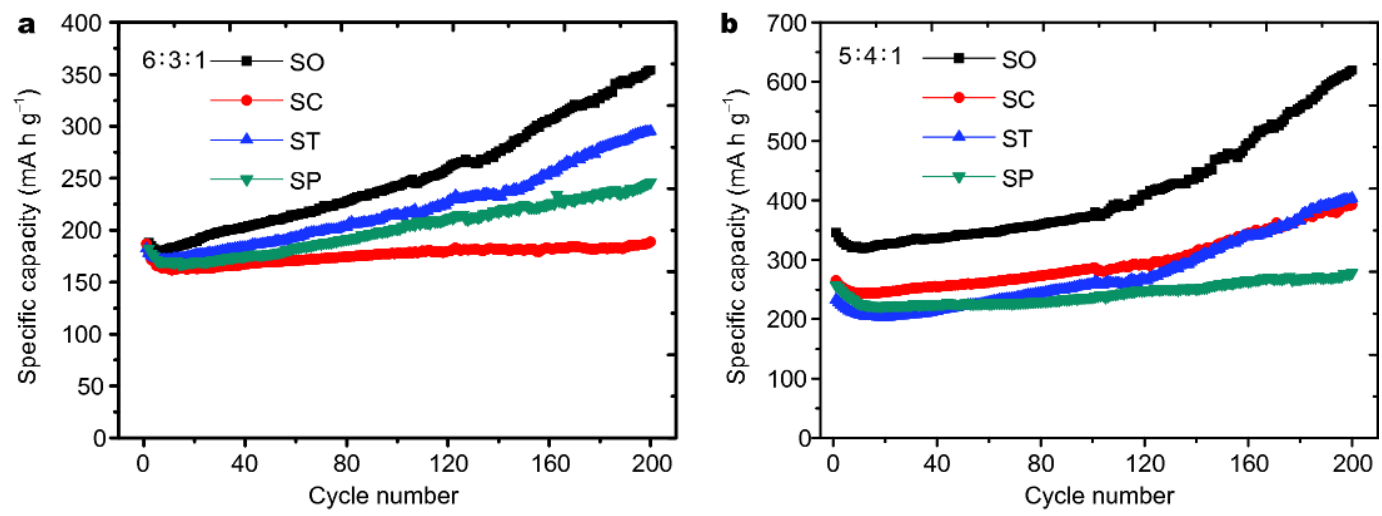

Figure 6 Cycling performance of SO, SC, ST and SP with different ratios of conductive agent: (a) 6:3:1 and (b) 5:4:1.
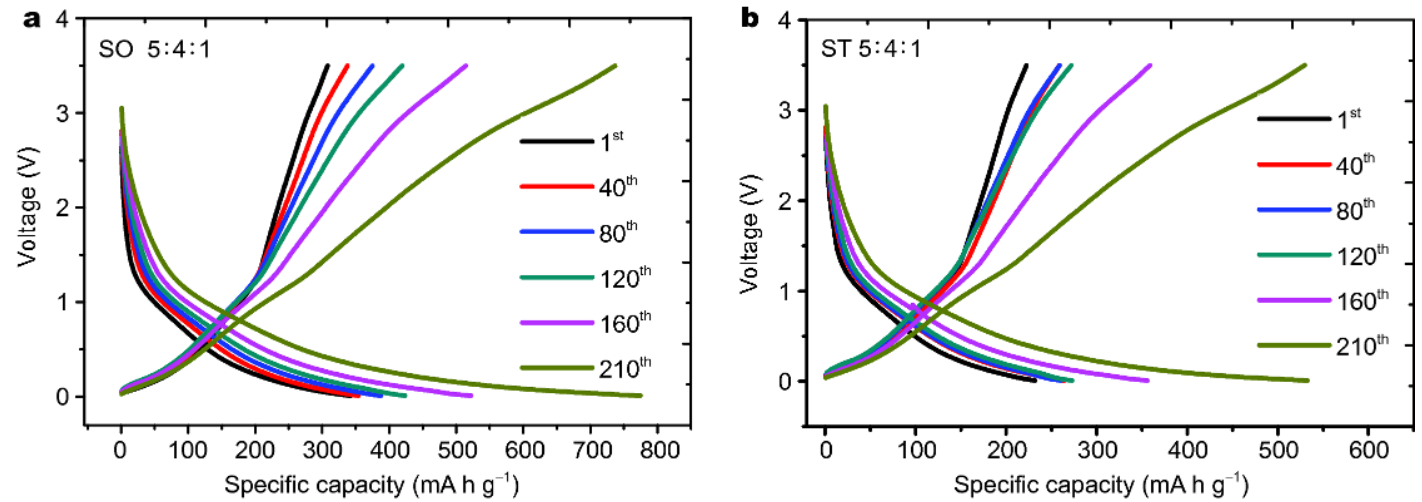

Figure 7 Charge and discharge curves of SO and ST electrodes at different cycle numbers.

Table 2. Cycling performance data of SO, SC, ST and SP with different ratios of conductive agent

\begin{tabular}{ccccc}
\hline Electrodes & $\begin{array}{c}\text { Theoretical capacity } \\
\left(\mathrm{mA} \mathrm{h} \mathrm{g}^{-1}\right)\end{array}$ & $\begin{array}{c}\text { Initial capacity } \\
\left(\mathrm{mA} \mathrm{h} \mathrm{g}^{-1}\right)\end{array}$ & $\begin{array}{c}200^{\text {th }} \text { capacity } \\
\left(\mathrm{mA} \mathrm{h} \mathrm{g}^{-1}\right)\end{array}$ & $\begin{array}{c}200^{\text {th }} \\
\text { capacity retention }\end{array}$ \\
\hline SO (6:3:1) & 399.8 & 187.9 & 354.2 & $188 \%$ \\
SC (6:3:1) & 311.4 & 186.8 & 295.3 & $101 \%$ \\
ST (6:3:1) & 276.1 & 182.3 & 246.1 & $162 \%$ \\
SP (6:3:1) & 313.3 & 182.4 & 619.6 & $135 \%$ \\
SO (5:4:1) & 399.8 & 345.6 & 392.3 & $179 \%$ \\
SC (5:4:1) & 311.4 & 264.9 & 403.7 & $148 \%$ \\
ST (5:4:1) & 276.1 & 232.8 & 278.1 & $173 \%$ \\
SP (5:4:1) & 313.3 & 256.9 & & $108 \%$ \\
\hline
\end{tabular}

tent of conductive agents is not high enough; a lower amount of conductive agent results in the activation of more active sites. During cycling, lithium ions are repeatedly inserted and removed from the interior of the active particles, resulting in the deep exfoliation of carboxylic acid sodium particles and the formation of smaller structural units, thus increasing the active points of lithium insertion. The above analysis can explain why the capacity initially decreases and then increases as the cycle number increases.

Fig. 7 shows the charge and discharge curves of the SO and ST electrodes at different cycle numbers. It can be seen that the charge and discharge capacities of the two electrodes increase rapidly with an increase in the cycle number, especially after the 100 cycles, where the capacity increases obviously. After 210 cycles, the discharge capacities of the SO and ST electrodes reached 532.7 and $774.6 \mathrm{~mA} \mathrm{~h} \mathrm{~g}^{-1}$, respectively, which is much higher than 
the theoretical capacity of a traditional graphite anode $\left(370 \mathrm{~mA} \mathrm{~h} \mathrm{~g}^{-1}\right)$. Although the charge/discharge capacities significantly improved, the voltage platforms and shapes of charge/discharge curves exhibit no obvious change, which indicates that no new species with better electrochemical activity are produced during the charging and discharging processes and the increase in charge/discharge capacity is due to the change in the morphology and structure of the active material itself.

This conclusion can also be seen from the SEM images of the electrode sheets with different cycle numbers. As shown in Fig. 8, the SEM images of the SO-541 electrode sheet with 200 cycles and the ST-541 electrode sheet with 50 cycles were contrasted with that of electrode sheet without charging and discharging. It can be clearly seen that the size of the active particles before cycling is relatively larger, i.e., approximately $10 \mu \mathrm{m}$, while after cycling for 200 times for SO-541 and 50 times for ST-541, large active particles break down into many smaller sizes, forming many cracks and pores, which not only enhance the surface area of the active substance but also greatly increase the transport of the lithium ions. This is the real reason why the electrochemical performance continues to improve as the cycle continues. With the cycling of charge and discharge process, the lithium ions will be embedded and extracted continuously. After a certain number of cycles, the electrolyte and $\mathrm{Li}$ ions are embedded into the active material together, resulting in the deep exfoliation of active particles, which may result in the formation of active particles. As a result, the surface area of active compounds increased, and more active sites were exposed, which clearly improved the charge and discharge capacities.

As the number of pores increased, the contribution to the capacity of the battery increased gradually. The capacities after 200 cycles even exceed the theoretical capacities (Table 2). In order to obtain more evidence to support this conclusion, we compared the EIS and CV curves with different cycles. As shown in Fig. S1 and Table S1 (see in supplementary information), the $R_{3}$ and $W_{1}$ values of ST and SP electrodes after 200 cycles became much smaller than that of ST and SP electrodes after three cycles (Fig. S1a and b), which indicates that the charge-transfer resistance of $\mathrm{Li}^{+}$during the electrochemical reaction process and the diffusion resistance of $\mathrm{Li}^{+}$in the solid electrode keeps decreasing as the cycle goes on. And also, we can see that the area of the CV curves after the 200 cycles are obviously larger than that of electrode without cycling (Fig. S1c and d), which indicates that the battery will produce greater capacity as

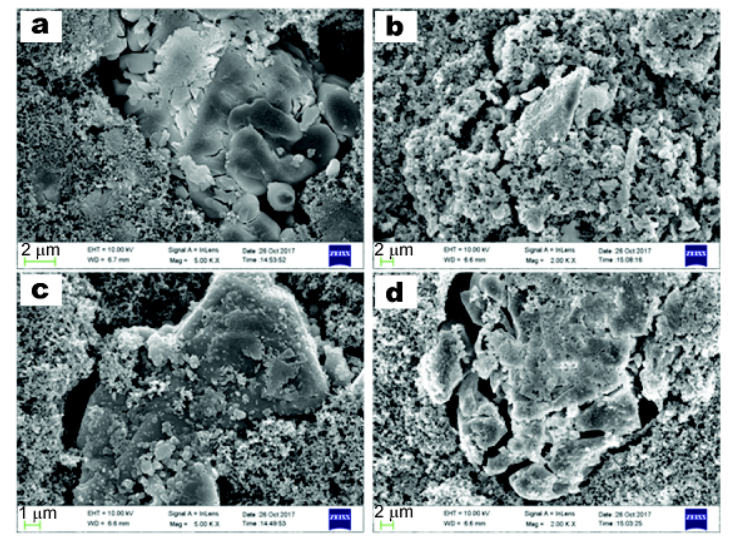

Figure 8 SEM images of SO-541 and ST-541 electrodes (a) SO-541 electrode without charging and discharging; (b) SO-541 electrode after 200 cycles; (c) ST-541 electrode without charging and discharging; (d) ST-541 electrode after 50 cycles.

the cycle goes on. These results are in good agreement with the change trend of surface morphology in Fig. 8, fully verifying the opinions we have speculated.

High amounts (30\%-40\%) of conductive carbon black were used in the electrode slurry. To understand the contribution of conductive additives on the electrochemical performance of sodium carboxylate salt electrodes, an electrode with a conductive agent (SP/ PVDF=90/10) (without sodium carboxylate salt) was prepared, and the battery was assembled with lithium metal as the counter electrode. The charge/discharge performance was tested and analyzed, as shown in Fig. S2. The results show that the initial capacity of the battery with conductive agent $(\mathrm{SP} / \mathrm{PVDF}=90 / 10)$ (without sodium carboxylate salt) is approximately $158 \mathrm{~mA} \mathrm{~h} \mathrm{~g}^{-1}$, and this value will decline with an increase in the cycle number. If the total contents of the SP conductive agent are $30 \%$ and $40 \%$, the capacities produced by the SP conductive agent will be approximately 47.4 and $63.2 \mathrm{~mA} \mathrm{~h} \mathrm{~g}^{-1}$, respectively. The initial and $200^{\text {th }}$ specific capacities of the sodium carboxylate salt electrodes (see in Table 2) contribute to the capacity, but the contribution ratio is not increased. For the sodium carboxylate saltbased electrodes, the main contribution to the capacity comes from the sodium carboxylate salt itself. The conductive agent improves the performance of the battery, and its contribution to the battery capacity is not obvious. The electrode of sodium carboxylate salt plays a leading role in the high capacity of the battery.

\section{Rate performance}

Fig. 9 presents the rate capabilities of SO, SC, ST, and SP discharging at different current densities from 50 to 

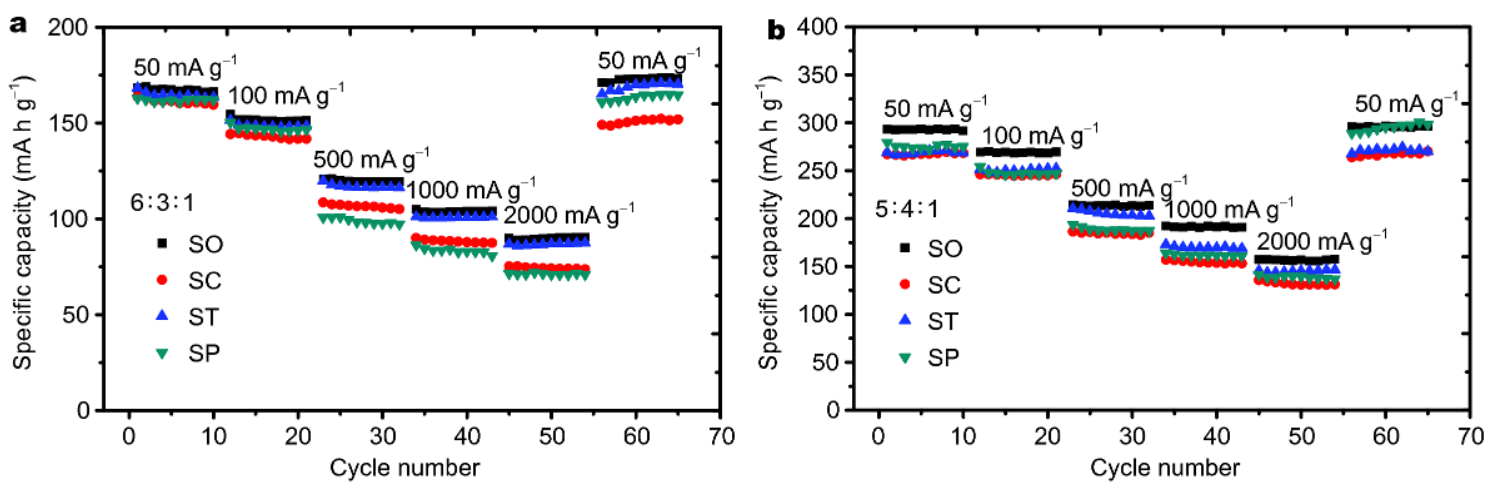

Figure 9 Rate performance of SO, SC, ST and SP with different ratios of conductive agent of (a) 6:3:1 and (b) 5:4:1 at various current densities from 50 to $2,000 \mathrm{~mA} \mathrm{~g}^{-1}$.

2,000 $\mathrm{mA} \mathrm{g}^{-1}$. Compared with the SC, ST and SP electrodes, the SO electrode presented the highest capacity and stability at each current density. For the electrodes with the $30 \mathrm{wt} \%$ conductive agent (Fig. 9a) at current densities gradually increasing from 50 to $100,500,1,000$ and $2,000 \mathrm{~mA} \mathrm{~g}^{-1}$, the average discharging capacities of SO decreased from 167.5 to $151.6,119.7,103.8$ and $89.9 \mathrm{~mA} \mathrm{~h} \mathrm{~g}^{-1}$, respectively. However, when the current density was reduced to $50 \mathrm{~mA} \mathrm{~g}^{-1}$, the average discharging capacity of SO still recovered to $173.5 \mathrm{~mA} \mathrm{~h} \mathrm{~g}^{-1}$, which is higher than that of the initial average capacity of $167.5 \mathrm{~mA} \mathrm{~h} \mathrm{~g}^{-1}$ at $50 \mathrm{~mA} \mathrm{~g}^{-1}$ due to the activation of active sites, as discussed previously for the cycling performance. Meanwhile, the discharge capacities of the SC, ST, and SP electrodes are always lower than that of the SO electrode at the same current density. Consequently, the SO electrode material presents the best rate capability, the SC electrode material displays the second-best rate capability, and the ST and SP electrode materials exhibit relatively low rate capacities.

Similar results are also observed for the electrodes with the 40 wt $\%$ conductive agent (Fig. 9b). With current densities increasing from 50 to $100,500,1,000$ and $2,000 \mathrm{~mA} \mathrm{~g}^{-1}$, the average discharging capacities of SO decreased from 293.6 to 269.4, 213.7, 191.7 and $157.1 \mathrm{~mA} \mathrm{~h} \mathrm{~g}^{-1}$, respectively. Excellent rate capacities are observed, even when discharging at the high current density of $2,000 \mathrm{~mA} \mathrm{~g}^{-1}$. Similarly, when the current density was reduced to $50 \mathrm{~mA} \mathrm{~g}^{-1}$, the average discharging capacity of $\mathrm{SO}$ recovered to approximately 296.6 $\mathrm{mA} \mathrm{h} \mathrm{g}^{-1}$, which is also slightly higher than the initial average capacity of $296.3 \mathrm{~mA} \mathrm{~h} \mathrm{~g}^{-1}$ at $50 \mathrm{~mA} \mathrm{~g}^{-1}$. At a high current density of $2,000 \mathrm{~mA} \mathrm{~g}^{-1}$, all the SC, ST and SP electrodes displayed discharge capacities of 131.3, 144.9 and $139.7 \mathrm{~mA} \mathrm{~h} \mathrm{~g}^{-1}$, respectively, indicating that the sodium carboxylate salts exhibited superior rate performance.

\section{Electrochemical mechanism}

As discussed in CV curves (Fig. 3), there are no obvious redox peaks observed in contrast to traditional metal oxide electrode materials, and all samples show much higher current responses at the lower voltage range of 0.01 to $1.5 \mathrm{~V}$ and much lower current responses at the higher voltage range of 1.5 to $3.5 \mathrm{~V}$, indicating that the polycarboxylic acid salts would base on a special lithium storage mechanism. For carbonyl compounds, the opening and closing of the double bonds of the carbonyl groups contribute to the capacity of the battery, as illustrated in Fig, 10a. In addition, the samples of polycarboxylic acid salts have the lattice spacing similar to graphite, which are very suitable for the intercalation and removal of lithium ions. In Fig. 10b, the charge-discharge curves have two distinct voltage platforms: $1.3-3.5 \mathrm{~V}$ with capacity contribution of $50-70 \mathrm{~mA} \mathrm{~h} \mathrm{~g}^{-1}$ and $0.01-1.3 \mathrm{~V}$ with capacity contribution of $150-200 \mathrm{~mA} \mathrm{~h} \mathrm{~g}^{-1}$ respectively, which can be attributed to the two different charge-discharge mechanisms.

As the cycle proceeds, the shape of the charge and discharge curve does not change significantly, still showing two different voltage platforms (Fig. 7), but the capacity contributed by each platform has been obviously increased. Especially, in the voltage range of 1.5 to $3.5 \mathrm{~V}$, the increase of capacity is greater, and this is due to the creation of more pore structures that results in much more naked carbonyl active sites. Therefore, we can infer that the capacity originating from the high voltage platform is contributed by the carbonyl group as illustrated in Fig. 10a, while the capacity at the low voltage platform is produced by porous/layered structure as expressed in Fig. 
a
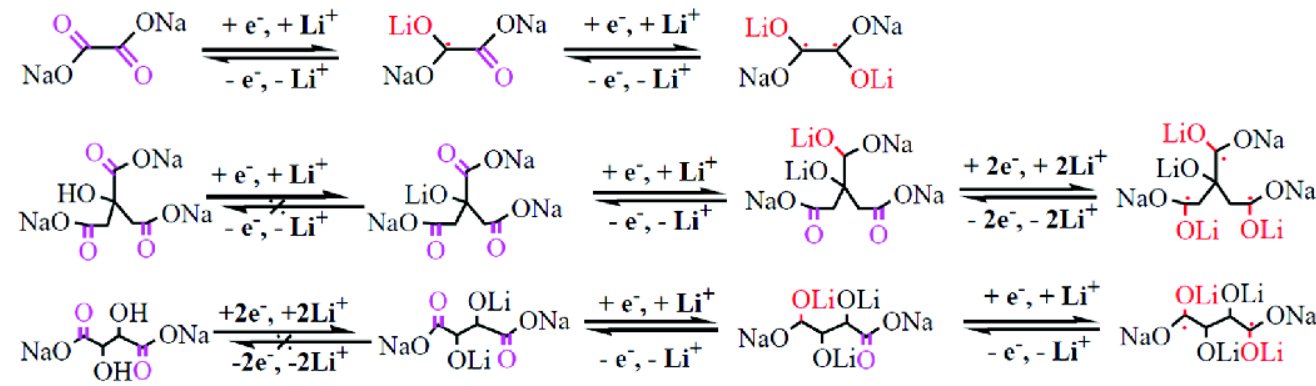

$(\mathrm{SP})$
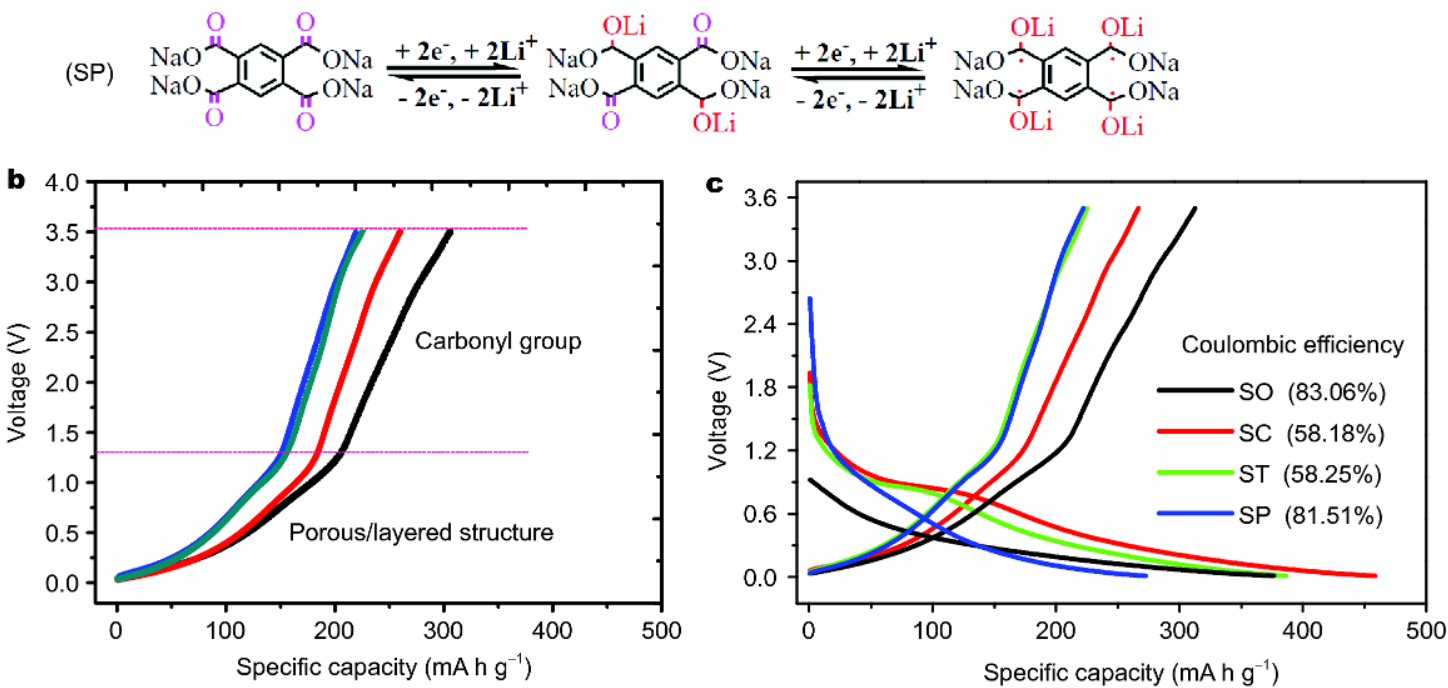

Figure 10 (a) Electrochemical reaction for carbonyl groups of the four polycarboxylic acid sodium samples of SO, SC, ST and SP; (b) two distinct voltage charging platforms caused by carbonyl groups and porous/layered structure; (c) pretreated initial charging/discharging curves of electrodes for the SO, SC, ST and SP salts $\left(3.5-0.01 \mathrm{~V}, 25 \mathrm{~mA} \mathrm{~g}^{-1}\right)$.

10b. This is also consistent with the charge-discharge platform of carbonyl groups reported in the literature [31].

For the SC and ST electrodes, their molecular structures contain hydroxyl groups, and the proton in the hydroxyl group will combine with lithium ions in the formation stage, resulting in irreversible capacity $[28,29]$. As shown in Fig. 10c, the change/duscgarge curves of electrodes for the four carboxylic acid sodium salts have been investigated and analyzed. It can be seen that the coulombic efficiencies for SO, SC, ST and SP are $83.1 \%, 58.2 \%$, $56.3 \%$ and $81.5 \%$, respectively. For the SO and SP electrodes, the irreversible capacity is mainly contributed from the formation of SEI films. While for the salts of SC and ST containing proton hydrogen, in addition to contribution from the formation of the SEI film, the irreversible capacity is also partly produced by the proton hydrogen on the hydroxyl group of the SC and ST molecular structures, and that is why their coulombic efficiencies are much smaller, and their initial discharge capacities of the first cycle are even higher than those of the SO and SP electrodes.

\section{CONCLUSIONS}

In summary, four sustainable sodium carboxylate-derived materials (SO, SC, ST and SP) were employed as novel high-performance electrodes for lithium-ion batteries. Due to differences in the symmetry of the molecular structure and intermolecular interactions, the following two different morphologies were formed: a porous structure with good regularity formed by the accumulation of spherical particles (SO, SP) and a porous structure with poor regularity formed by irregularly layered particles. The initial capacity was first attenuated due to the formation of an SEI film, and then the capacity increased as cycling proceeded due to the deep exfoliation of carboxylic acid sodium particles and the formation of smaller structural units, which increased the active points of lithium insertion. As a result, a high reversible capacity, excellent cycling stability and a superior rate cap- 
ability were observed for the four sodium carboxylatederived materials. The excellent electrochemical properties, as well as the natural abundance and low cost, make sodium carboxylate-derived materials promising low-cost electrode materials for large-scale lithium-ion batteries. The sodium carboxylate-derived materials investigated in this work expand the scope of novel organic sustainable electrode materials with superior electrochemical performance.

Received 11 November 2017; accepted 5 January 2018; published online 26 February 2018

1 Armand M, Tarascon JM. Building better batteries. Nature, 2008, 451: $652-657$

2 Tang Z. Non-noble metal anode based dual-ion batteries: promising high-energy and low-cost energy storage devices. Sci China Mater, 2017, 60: 368-370

3 Goodenough JB, Kim Y. Challenges for rechargeable Li batteries. Chem Mater, 2010, 22: 587-603

4 Zhang Q, Huang Y, Liu Y, et al. F-doped O3-NaNi $\mathrm{Na}_{1 / 3} \mathrm{Fe}_{1 / 3} \mathrm{Mn}_{1 / 3} \mathrm{O}_{2}$ as high-performance cathode materials for sodium-ion batteries. Sci China Mater, 2017, 60: 629-636

5 Goodenough JB, Park KS. The Li-ion rechargeable battery: a perspective. J Am Chem Soc, 2013, 135: 1167-1176

6 Wang L, Hu Z, Zhao K, et al. Hollow spherical $\mathrm{LiNi}_{0.5} \mathrm{Mn}_{1.5} \mathrm{O}_{4}$ built from polyhedra with high-rate performance via carbon nanotube modification. Sci China Mater, 2016, 59: 95-103

7 Choi NS, Chen Z, Freunberger SA, et al. Challenges facing lithium batteries and electrical double-layer capacitors. Angew Chem Int Ed, 2012, 51: 9994-10024

8 Liang Y, Tao Z, Chen J. Organic electrode materials for rechargeable lithium batteries. Adv Energy Mater, 2012, 2: 742-769

9 Song Z, Zhou $\mathrm{H}$. Towards sustainable and versatile energy storage devices: an overview of organic electrode materials. Energy Environ Sci, 2013, 6: 2280-2301

10 Häupler B, Wild A, Schubert US. Carbonyls: powerful organic materials for secondary batteries. Adv Energy Mater, 2015, 5: 1402034

11 Yang S, Feng X, Müllen K. Sandwich-like, graphene-based titania nanosheets with high surface area for fast lithium storage. Adv Mater, 2011, 23: 3575-3579

12 Zhang $\mathrm{K}, \mathrm{Hu} \mathrm{Z}$, Tao Z, et al. Inorganic \& organic materials for rechargeable Li batteries with multi-electron reaction. Sci China Mater, 2014, 57: 42-58

13 Zhang L, Liu Z, Cui G, et al. Biomass-derived materials for electrochemical energy storages. Prog Polymer Sci, 2015, 43: 136-164

$14 \mathrm{Wu} \mathrm{H}$, Shevlin SA, Meng Q, et al. Flexible and binder-free organic cathode for high-performance lithium-ion batteries. Adv Mater, 2014, 26: 3338-3343

15 Zhang K, Guo C, Zhao Q, et al. High-performance organic lithium batteries with an ether-based electrolyte and 9,10-anthraquinone (AQ)/CMK-3 cathode. Adv Sci, 2015, 2: 1500018-1500024

16 Xie J, Wang Z, Gu P, et al. A novel quinone-based polymer electrode for high performance lithium-ion batteries. Sci China Mater, 2016, 59: 6-11

17 Huang W, Zhu Z, Wang L, et al. Quasi-solid-state rechargeable lithium-ion batteries with a calix[4]quinone cathode and gel polymer electrolyte. Angew Chem Int Ed, 2013, 52: 9162-9166

18 Chen H, Armand M, Demailly G, et al. From biomass to a renewable $\mathrm{Li}_{x} \mathrm{C}_{6} \mathrm{O}_{6}$ organic electrode for sustainable Li-ion batteries. ChemSusChem, 2008, 1: 348-355

19 Ang WA, Gupta N, Prasanth R, et al. High-performing mesoporous iron oxalate anodes for lithium-ion batteries. ACS Appl Mater Interfaces, 2012, 4: 7011-7019

20 Oh HJ, Jo CH, Yoon CS, et al. Nickel oxalate dihydrate nanorods attached to reduced graphene oxide sheets as a high-capacity anode for rechargeable lithium batteries. NPG Asia Mater, 2016, 8: e270

21 Wang S, Wang L, Zhang $\mathrm{K}$, et al. Organic $\mathrm{Li}_{4} \mathrm{C}_{8} \mathrm{H}_{2} \mathrm{O}_{6}$ nanosheets for lithium-ion batteries. Nano Lett, 2013, 13: 4404-4409

22 Luo C, Huang R, Kevorkyants R, et al. Self-assembled organic nanowires for high power density lithium ion batteries. Nano Lett, 2014, 14: 1596-1602

23 Suo L, Hu YS, Li H, et al. A new class of Solvent-in-Salt electrolyte for high-energy rechargeable metallic lithium batteries. Nat Commun, 2013, 4: 1481-1849

24 Armand M, Grugeon S, Vezin H, et al. Conjugated dicarboxylate anodes for Li-ion batteries. Nat Mater, 2009, 8: 120-125

25 Chen $\mathrm{H}$, Armand $\mathrm{M}$, Courty $\mathrm{M}$, et al. Lithium salt of tetrahydroxybenzoquinone: toward the development of a sustainable Li-ion battery. J Am Chem Soc, 2009, 131: 8984-8988

26 Yang X, Li C, Zhang G, et al. Polystyrene-derived carbon with hierarchical macro-meso-microporous structure for high-rate lithium-ion batteries application. J Mater Sci, 2015, 50: 6649-6655

27 Lei Z, Wei-kun W, An-bang W, et al. A MC/AQ parasitic composite as cathode material for lithium battery. J Electrochem Soc, 2011, 158: A991-A996

28 Chen J, Zhang Q, Zeng M, et al. Carboxyl-conjugated phthalocyanines used as novel electrode materials with high specific capacity for lithium-ion batteries. J Solid State Electrochem, 2016, 20 : 1285-1294

29 Chen J, Guo J, Zhang T, et al. Electrochemical properties of carbonyl substituted phthalocyanines as electrode materials for lithium-ion batteries. RSC Adv, 2016, 6: 52850-52853

30 Wang $\mathrm{Y}$, Chen J, Jiang $\mathrm{C}$, et al. Tetra- $\beta$-nitro-substituted phthalocyanines: a new organic electrode material for lithium batteries. J Solid State Electrochem, 2017, 21: 947-954

31 Yokoji T, Kameyama Y, Maruyama N, et al. High-capacity organic cathode active materials of 2,2'-bis-p-benzoquinone derivatives for rechargeable batteries. J Mater Chem A, 2016, 4: 5457-5466

32 Yao M, Senoh H, Sakai T, Kiyobayashi T. 5,7,12,14-Pentacenetetrone as a high-capacity organic positive-electrode material for use in rechargeable lithium batteries. Int J Electrochem Sci, 2011, 6: 2905-2911

33 Xiong D, Li X, Shan $\mathrm{H}$, et al. Controllable oxygenic functional groups of metal-free cathodes for high performance lithium ion batteries. J Mater Chem A, 2015, 3: 11376-11386

34 Churikov AV, Romanova VO. Determination of diffusion coefficient of lithium in substituted $\mathrm{LiMn}_{1.95} \mathrm{Cr}_{0.05} \mathrm{O}_{4}$ spinel using impedance technique. Russ J Electrochem, 2013, 49: 272-277

Acknowledgements This work was supported by the National Natural Science Foundation of China (21762019 and 51372104), the Science and Technology Project of Jiangxi Province (20161BAB213082, 20171BAB 206017 and 20151BAB206018), the Science Research Project of Jiangxi Provincial Department of Education (GJJ150672), and the College Students Innovation and Entrepreneurship Project (201610407006, and XZG-16-08-17). 
Author contributions Chen J designed the experiments, performed the data analysis and wrote the article. Xu Y performed the experiments, assembled the cells and tested the electrochemical performance. Zhu C tested and analyzed the SEM and XRD patterns. Zhang W performed partial experiments and tests. Jiang $\mathrm{G}$ and Wang $\mathrm{C}$ performed and analyzed partial electrochemical performance such as EIS and CV curves. Zhang $\mathrm{Q}$ and Ding $\mathrm{N}$ performed the data analysis. Huang YX engineered the samples. Zhang Q and Zhong SW contributed to the theoretical analysis. All authors contributed to the general discussion.

Conflict of interest The authors declare no conflict of interest.

Supplementary information Supporting data are available in the online version of the paper.

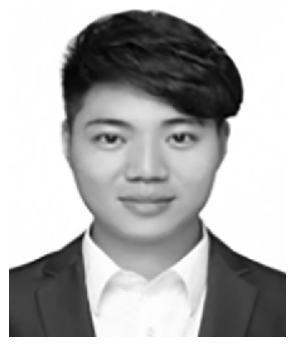

Yong Xu received his BSc degree in Materials Engineering from Jiangxi University of Science and Technology (2016). He then joined the Key Laboratory of Power Battery and Materials as a Master student under the supervision of Associated Prof. Jun Chen. His research focuses on organic electrode materials for rechargeable batteries.
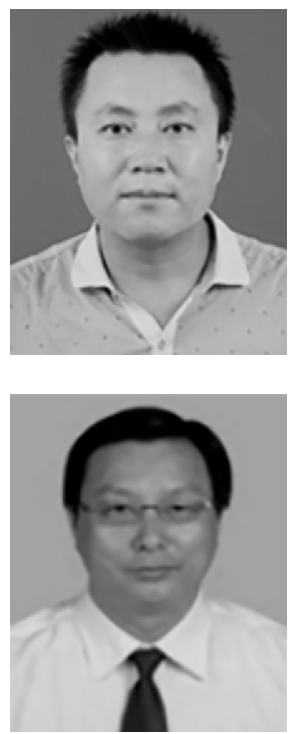

Jun Chen received his $\mathrm{PhD}$ in organic chemistry under the supervision of Prof. Guoqiang Yang from the Institute of Chemistry, Chinese Academy of Sciences in 2009. He has been an associated professor at Jiangxi University of Science and Technology since 2014. His current research interest focuses on organic functional materials for energy storage and optoelectronic devices.

\begin{abstract}
Shengwen Zhong is a leading personnel of the National Ten Thousand Talent Program at Jiangxi University of Science and Technology. He is the director of the Key Laboratory of Power Battery and Materials. His research focuses on high power battery and energy storage materials for rechargeable batteries.
\end{abstract}

\section{高性能羧酸钠盐衍生物作为电化学储能材料}

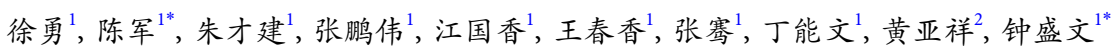

摘要 本文选取四种羧酸钠盐化合物, 研究了它们作为新型锂离子电池电极材料的电化学性能. 结果表明, 由于分子间相互作用产生的多 孔形态, 羧酸钠盐衍生材料显示出逐渐增加的容量、优良的循环稳定性和倍率性能. 对于SO-541(草酸钠)、SC-541(柠檬酸钠)、St-541(酒 石酸钠)和SP-541(均苯四甲酸钠)电极材料, 在 $50 \mathrm{~mA} \mathrm{~g}^{-1}$ 的电流密度下, 200 次循环后的容量仍保持在 $619.6,392.3,403.7$ 和 $278.1 \mathrm{~mA} \mathrm{~h} \mathrm{~g}^{-1}$, 容量保持率分别为 $179 \%, 148 \%, 173 \%$ 和 $108 \%$, 甚至在 $2000 \mathrm{~m} \mathrm{~A} \mathrm{~g}^{-1}$ 的高电流密度下, 其容量仍分别保持在 157.6, 131.3, 146.6 和 $137.0 \mathrm{~mA} \mathrm{~h} \mathrm{~g}^{-1}$. 这些优异的电化学性能, 使羧酸钠衍生材料有望成为大型锂离子电池的有机电极材料. 